\title{
INFECTION AND NATURE OF THE YELLOW STRIPE DISEASE OF CANE (NIOSAIC, MOTTLING, ETC.)
}

\author{
By J. Matz.
}

\section{INTRODUCTION.}

In December, 1918, the writer began studies of this disease in Porto Rico. The following is a summary of experiments and histological studies made during a period of twelve months. Owing to the conflicting views among investigators regarding the nature of this disease there could not be obtained much guidance as to any one definite line of investigation to follow out, so that even previous experiments carried out by others had to be repeated in order to gain a clear path for any line of investigation.

In reviewing the literature on this disease it was found that although the disease has been recorded to have appeared in cane fields which were previously known to be free from any visible signs of it, yet there is hardly any records of exact observations of its transmissibility to known healthy plants. There is no doubt that a large part of the spread of the disease is due to the use of infected seed, but it is also an undeniable fact that new or secondary infections occur. This is supported by records of observations made in Porto Rico, Java, Hawaii and Cuba. It would be erroneous to assume that healthy cane showing new cases of yellow striping had in actuality the disease in such a dormant state as not to show its symptoms up to a period of several months or more. Tests as to dormaney were made, at the beginning of this work here, with seed pieces from cane which were in a not advanced stage of the disease. Portions of these canes were cut into pieces having one or two eyes each and placed in glass moist chambers for germination. The cane and glass chambers were sterilized to remove molds and bacteria. In forty-five trials, using cane from three different sources, not a single case was found where the symptoms of the disease were not observable in the unfolding leaves in the shoots of diseased seed. Diseased seed always produced diseased plants; in other words, if the disease is present in the cane it will show up at an early stage in 
the leaves, by its characteristic symptoms. Further tests aiong this line were made by planting diseased seed pieces in sterilized and unsterilized soil, in pots. Ifere the results were the same only with a slightly higher accentuation of the symptoms in unsterilized soil due to the fact that the seed piece breaks down quicker by the aid of ferments and fungi which sometimes abound in such soils, thus aiding in the stunting and deterioration of the young buds. In the unsterilized soil the young shoots became, in addition to the yellow striping, speckled with a reddish tinge, and formed a shorter stem with the leaflets growing in more or less of whorls.

There is the possibility of the symptoms being so faint as to evade detection to the casual observer. The various symptoms of the disease on different varieties of cane have been described in previous publications, and it is plain that the disease can be recognized in all instances. However, the writer had under observation fom: plants in pots which showed only an occasional thin stripe of a darker green on a field of lighter green. These plants were kept up in good condition having applied to them a liberal amount of nitrate with frequent watering. The symptoms of yellow stripe always existed in these plants in the older canes but in a rather less pronounced form. The young shoots, however, which occassionally come up at the bases of these canes show the symptoms more distinctly. Other plants, diseased, and growing under the same condition close to the above show the disease very clearly and distinctly. On the other hand the same variety, Crystalina, is known to produce clearly distinct symptoms upon its becoming diseased in the field. The above four plants are kept for further observations. A degree of severity exists in the different fields and in individual eane plants. The severity of the disease depends, as has already been observed by others, on varietal resistence, length of time the disease is propagated in a given plant, and local conditions under which the cane is growing. In an infection experiment conducted in the greenhouse of the Insular Fxperiment Station, mention of which was made in last year's report, the "canker" stage was observed to have occurred in a cane in three months from the time when the first signs of the disease were noticed. This is contrary to views held by others, $i$. e., that it takes a certain number of generations for the canker stage to arise. It was really the general unfarorable conditions for the growth of the plant, as it was grown for almost a year in a fivegallon tin can, that helped the canker stage to be shown up sooner. 


\section{Contact.}

Dning the first part of this year experiments such as have been tried by others have been repeated in order to gain an intimate knowledge of the behavior of the disease. Healthy and diseased p'ants were planted together in the same pots; healthy and disrased seed pieces were split in half, and then a diseased half and a healthy half were fastened together and planted. There were no transmissions of the disease to the healthy plants. The healthy plant, though in contact with the diseased plant, has not contracted the disease. The healthy seed produced healthy shoots right alongside the diseased seed and shoots in the same pot. Healthy seed pieces were watered with water in which diseased cane was allowed to stay for some time. No infection occurred.

An experiment was made to find out if the disease could be transmitted through the roots. Diseased tissue was fastened onto the root eyes of healthy seed, so that the growing rootlet may come in contact with the cut surface of the diseased tissue. Eight of the healthy seed pieces germinated and the shoots were healthy. After four months in the pots two shoots of the healthy seed showed symptoms of yellow stripe. The experiment was repeated but gave negative results. The fact that the symptoms were belated in showing up would indicate that the two plants became infected through another source. There were diseased cane in the greenhouse.

Another experiment was made in the following manner: Healthy and diseased seed pieces were cut to contain three dormant buds each. The middle buds were carefully cut ont with a sharp knife. Care was taken to make the cut at least one-half inch on all sides from the bud, in order to leave uninjured root eyes and some tissue for the growth of the bud. The buds from the healthy seed were then inserted in the diseased seed in the places of diseased buds and the buds of the diseased seed were inserted in the healthy seed. Practically all of the buds germinated and from the first no transfer of the disease was observed to have taken place either in the healthy seed with the diseased buds or in the healthy buds inserted in the diseased seed. The grafts thus made did not live long but the seed in which they were inserted developed sound shoots from their original two remaining buds. It was thought that by bringing in contact the cut ends of the vascular systems of diseased and healthy cane a transmission of the disease might take place. But no infection occurred in this experiment. 


\section{Juice.}

Experiment 1.-On April 16, an experiment was made in the folowing manner: Five cane plants of about 8 months old, growing in five-gallon tin cans in the greenhouse of the Insular Experiment Station were examined and found free from any symptoms of yellow-stripe disease. Each of these plants consisted of one single stalk of about one inch in diameter and averaging about three feet in height. At the bases of each were one or more shoots of about six inches in height. These shoots also were free from yellow-stripe disease symptoms. The five stalks were eut back leaving stumps of abont four inches above ground, the shoots were left as they were. Jnice from a yellow-striped piece of cane was pressed out and injected, with a hypodermic needle, into the stumps near the surface of the ground. On April 28 typical symptoms of yellow stripe was observed in the lower parts and along the mid ribs of the central leaves of two shoots in two out of the five pots. At first only a few, larger, light green, narrow areas were noticed; later these light green areas spread all over the leaves and they became patterned with short alternating light-green and green stripes. In one of the two pots which showed infection on the 28th of April there were two shoots at the base of the old stalk but only one shoot showed infection on that date; however, about a week later the other shoot became infected. In three months the infected stalks have become more or less shrunken at the internodes and showed typical cases of the "canker" stage. The other three plants remained free from the disease throughont the experiment which lasted ten months. In this and later experiments the positions of the plants were noted and they were kept in the original places throughout.

The Position of Plants in Experiment 1.

\begin{tabular}{c|c|c|c|c|c}
\hline & \multicolumn{5}{|c}{ Plants inoculated April 16 } \\
\hline No.1 & No. 2 & No.3 & No.4 & No.5 \\
\hline April 28......... & free & diseased & free & diseased & tree \\
\hline
\end{tabular}

Experiment 2.-On May 1 a similar experiment was made in the same greenhouse with similar plants. Twenty plants were inoculated with juice from diseased cane and 20 were left uninoculated as cheeks On May 14 two of the inoculated plants showed the symptoms of the yellow stripe disease. These plants are marked " $D$ " in the next table. 
The positions of the pots in this experiment were thus:

Bench 1:

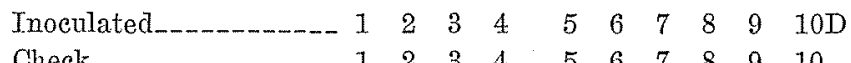

Bench 2.

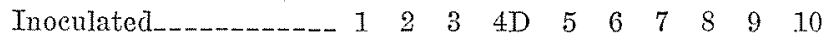

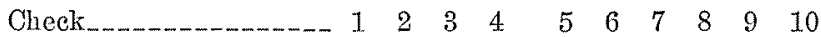

Experiment 3.-On the same date as the last experiment 10 plants were cut back only a little above the growing point, 5 of these were inoculated in the cut surface of the top by injecting diseased juice with a hypodermic needle, and 5 were left as checks. All of these have remained free from the disease.

Experiment 4.-On May 2, 25 healthy stools about three months old were transplanted from the field to the greenhouse in pots. The plants were cut back as in the first two experiments and 8 of these were inoculated with diseased juice and tissue; that is, in addition to the injection of juice, pieces of diseased cane were forced into small holes in the stems. All 25 plants remained free up to October when one of the checks developed the yellow-stripe disease symptoms. It must be stated that the four plants which developed the disease in the first experiments were of a lot of cane which were more mature than the last 25 plants. In order to test this point 18 seed pieces of mature Crystalina cane were cut to one or two eyes, 12 of these were inoculated near the base of the bud, by boring a hole into the seed piece three-quarters inch deep and directly into it was pressed juice from diseased cane, and 6 were inoculated in the same way with healthy cane juice. All were planted in pots and placed in the greenhouse.

Experiment 6.-At the same time 35 Crystalina stools in a field that has just been cut were inoculated with juice in the stubble near the bases of sprouting buds. In both of these last two experiments not a single positive case developed. The plants in the pots were transplanted, after four months in the greenhouse, to an open field, and up to the present no signs of the disease have become visible.

\section{NATURAL AND SECONDARY INFECTION.}

Experiment 7.-During the time when the above experiments were made there has not come to the writer's notice a case of second- 
ary infection in the greenhouse, nor were there any such cases reported previously. This was rather strange as secondary infections were being picked up every two or three weeks in the adjacent cane fields. The greenhouse was not "insect proof." In order to make sure that secondary infections do occur in known healthy cane, 48 seed pieces from three healthy and mature Crystalina canes were planted in pots and placed in the greenhouse. After two months from germination three of the 48 showed symptoms of yellow-stripe disease. However, these three plants, together with a number of others of the same lot, were on the ground instead of on a bench.

Experiment 8.-So another series of 50 seed of three healthy white Otaheita cane were planted in pots and all were placed on clean benches. In about three months from germination one of two shoots from two separate seed pieces in the same pot became distinetly diseased.

Experiment 9.-Ten cane stools having been cut back and transplanted from the field to pots in the greenhouse have been allowed to grow for four months. These showed no signs of yellow-stripe disease during that period. At the end of four months they were cut back and allowed to sprout again. One shoot began to show yellow-stripe disease in the unfolding leaves, and in two weeks the entire stool became diseasd.

Experiment 10.-On May 15 five healthy stools in five pots were inoculated with diseased juice in the stalks near the root crowns. Up to September no symptoms of yellow-stripe disease have developed. During the first part of September the plants were all cut back and aliowed to sprout up again, and two plants began to show the yellow-stripe disease in the central unfolding leaves of their shoots. It is assumed that these were secondary infections. It is of interest to note the development of the disease in one of these pots.

The position of the row of pots on the bench was thus: $\begin{array}{llll}1 & 2 & 3 & 4.5\end{array}$

Numbers 2 and 5 became diseased. No. 5 had two small cepas of 5 to 7 shoots. Both cepas came out from two original buds on the sides of a single seed piece. At first one cepa showed the disease, the symptoms of yellow stripe appearing first in one shoot and then in another until all became visibly infected. In about three weeks the second cepa became diseased, and again a gradual spread of the disease from one shoot to another was observed. In all of these shoots 
the central leaves always showed the symptoms first. It appears that the disease gradually communicates from one shoot to another through a common channel.

It is quite certain from observations made on healthy and diseased plants grown in close contact with one another, that mere surface contact does not transfer the disease to healthy plants. In the greenhouse a row of 10 diseased plants were placed alongside of a row of 10 healthy plants, allowing for contact between the healthy and diseased leaves, and not a single case of new infection resulted. However, during the late part of the summer a healthy plant which was adjacent to a diseased one in the greenhouse became diseased. This is the first case of its kind in the greenhouse, its occurrence should rather be layed to an outside agent rather than to its being close to a diseased plant.

The occurrence of yellow stripe in the greenhouse has been in all features similar to the way it works in the field. It attacks the young shoots and it is sporadic in location, it picks out a plant here and there only and there is not a general spread taking in complete areas. In the field a new infection may sometimes be observed on large cane, but from personal and close watch of the plants in the greenhouse secondary infection on more or less grown cane has not been seen.

The following conclusions can be drawn from the above observations; first that healthy cane from healthy seed became infected with the yellow-stripe disease; and secondly that the disease has been transferred artificially to healthy plants in four cases at least. It should be observed that in both, Nos. 1 and 2 experiments, the disease showed up in about two weeks from inoculation and there were no other new infections in the other plants in the greenhouse at that time. However, the exact method to insure takes is not known as yet. The prevailing idea that insects are the carriers of this disease is highly plausible, but the writer has not taken up this phase of the problem.

\section{IIISTOLOGICAI STUDIES.}

Histological studies of yellow-striped cane were made with the view to determine if possible in what way the disease affects the tissue of the host. A search for abnormalities in the interior of the cane stalk and leaves of diseased plants was made. Tissue from dis- 
eased mature cane stalks, from underground parts, from growing points and from leaves were cut with a sharp razor free hand and with the microtome. In studying microscopic sections of the outer cankered tissues of yellow-striped cane it was noticed that sometimes the parenchyma as well as collenchyma cells of the discolored areas possess very distinct, single, spherical, darkly colored and dense protoplasmic bodies. At first glance these resemble spore bodies of some organism. (Fig. $1 a, b$.) These bodies were also found in the centre of diseased cane. In searching in the tissues of non-yellow striped cane it was found that these bodies also exist in parenchyma cells there. It was found in the base of a young stalk which was

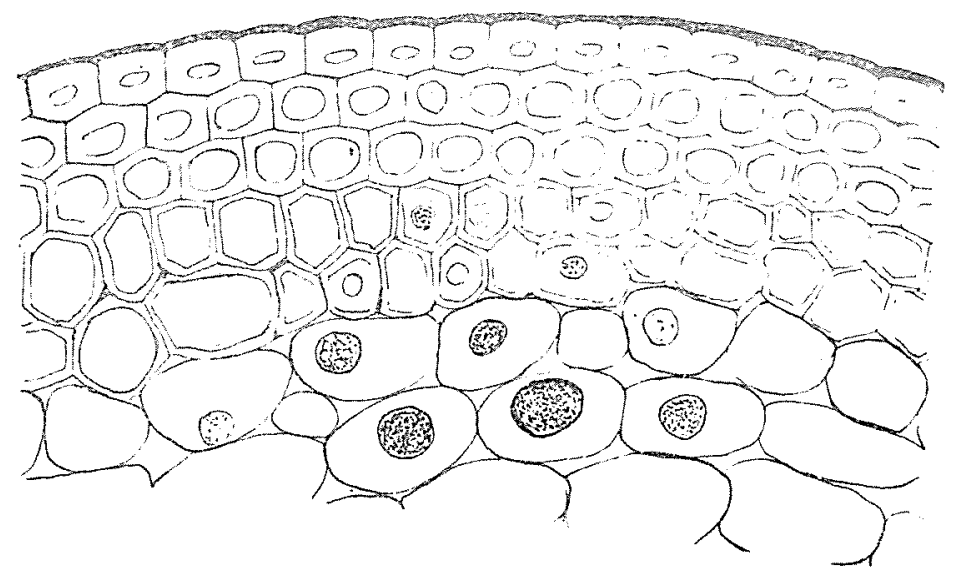

FIG. 1 a.-Dense and deeply colored nuclei in cane tissue near the rind. Drawing of a free-hand section from a yellow-stripe diseased stalk. $(\times 150$.

injured by a mechanical agent, it was found in the cells of roots of non-yellow striped cane and in the injured part of a stalk of cane of the same nature. It seems clear enough that under certain conditions of growth the nuclei of certain cells become dense and deeply colored and give the appearance of dense granulation when influenced by an inhibitory or injurious factor. Sections of tissue containing the spherical bodies refered to above could not be permanently mounted in the usual way as alcohol dissolves those bodies. When placing a free hand section in alcohol the spherical bodies become vacuolated and ultimately disappear from view, only a very thin wall being left. 
Paraffin sections of the uppermost nodes of yellow-striped and healthy cane were made. It was observed that a difference in the appearance of their respective tissues existed (Figs. 2, 3, and 4).

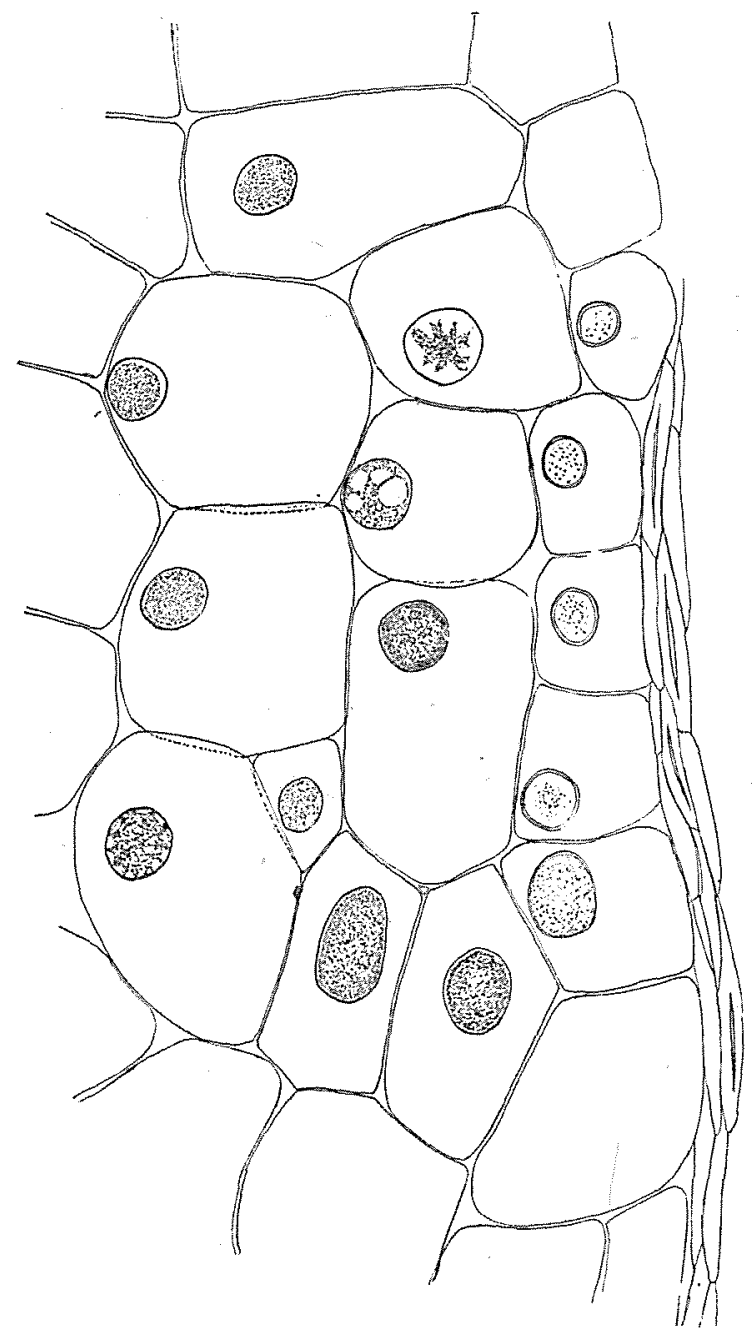

FIG. 1 b.-Drawing of similar bodies as in Fig. $1 a$, in cells of non-yellow stripe but otherwise injured cane tissue. $(\times 250$.

In the diseased tissues some of the parenchyma cells between the fibro-vaseular bundles were filled with a protoplasm which was dense and finely granulated, the bundles showed apparently the same sub- 
stance in the sieve tubes and vessels, ${ }^{1}$ while in the cells of the healthy cane the fibro-vascular bundles were free and the parenchyma between the bundles contained scattered and coarser granules. The last named are common in ent and exposed portions of young growing parts of cane.

Leaves of about the same age of healthy and yellow-striped cane were studied. Figures 5 and 6 show a striking difference in the appearance of the two. The healthy leaf in cross section shows no abnormality except slight shrinkage; in the diseased leaf some of

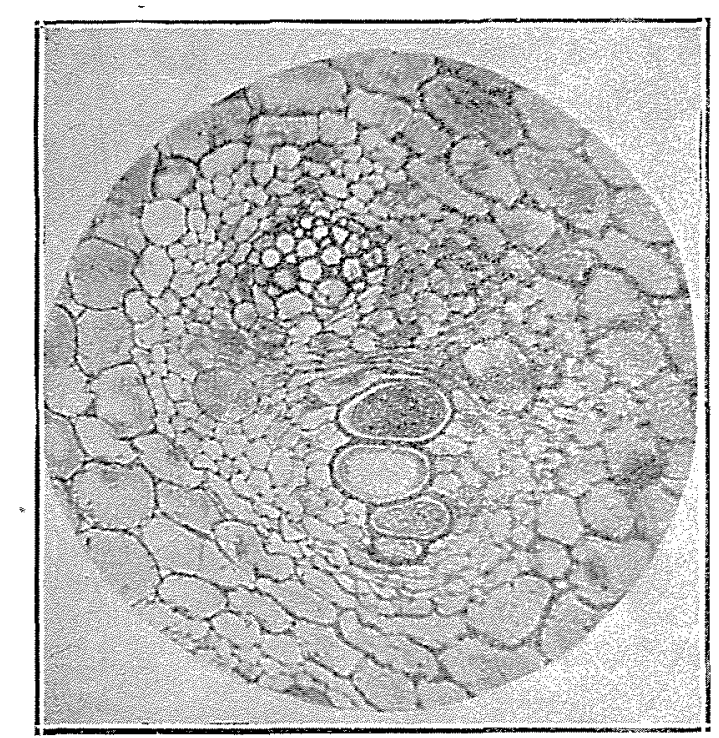

FIG. 2.-Photograph of a vasenlar bundle from near the growing point of yellow-stripe diseased eane, showing the finely granular substance in the vessels. $(\times 50$.

the epidermal cells, especially near the stomata, and some internal cells show dense contents which is colored slightly brown, and which is similar in appearance to the abnormalities found in the cells of the cane stem. It seems that a foreign plasmodium-like substance is apparently present in the cells of the yellow-striped cane leaf and stem tissue.

IThe writer has of late seen specimens of cane affected with gum disense due to $B a c$. terium vaseularm. This disease is distinctly different from the yellow-stripe disense, the gum of the former is yellow and full of bacteria which are easily eultured. No slimy exu. dation occurs in yellow-stripe disease. 
Further research along this line revealed the presence of the above plasmic substance more constantly and in a more defined form in "cankered" cane stalks. In investigating the histology of "cankered" cane a feature, which has not been mentioned before in the literature on the subject, has been noticed. Cankers have been characterized as exterior symptoms consisting of a few outer layers of

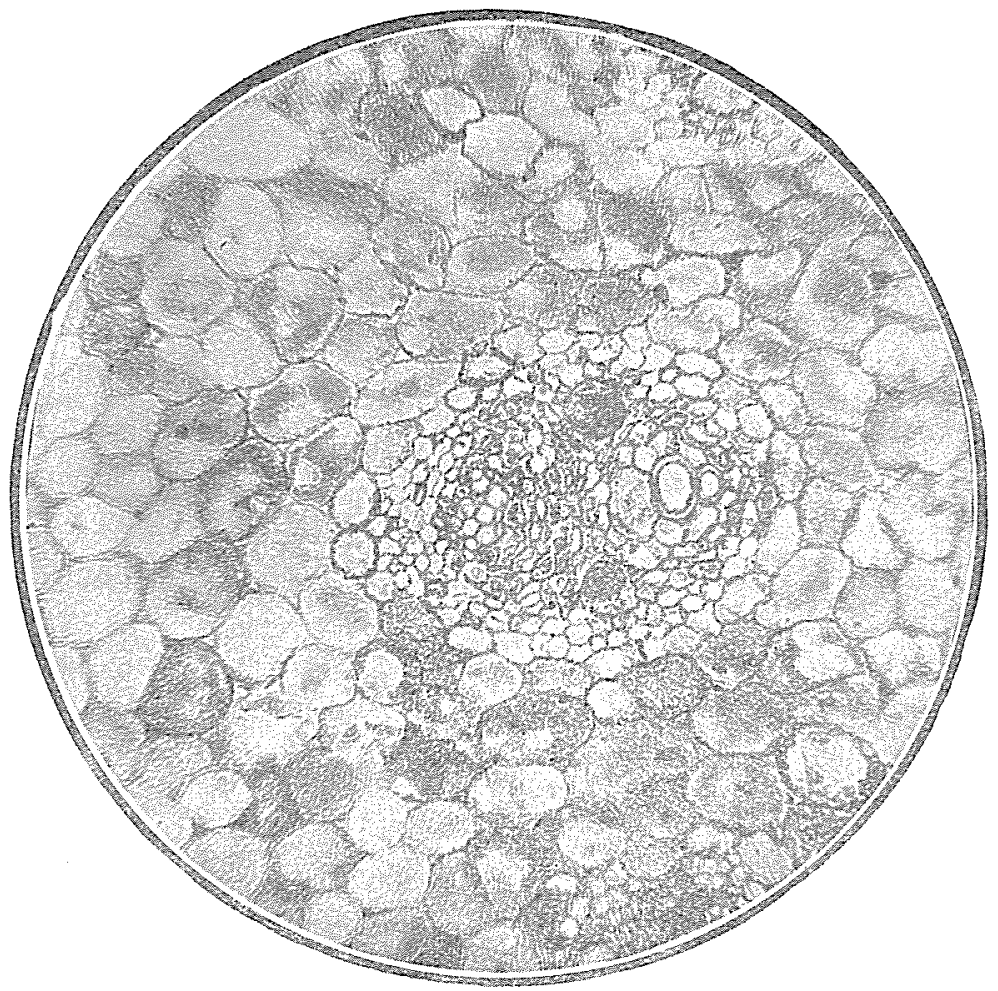

Fia. 3.-Photograph of a cross section through a growing point of yellow stripe diseased eane. Note the character of the parenchyma cells and compare with Fig. 4.

deteriorated cells, but in reality one may find separate and distinct pockets of brown to reddish-brown tissue deep in the interior throughout cankered cane. More often such a discolored region may be found in the form of a short streak, several centimeters in length. usually very close to the rind of the stalk, but these streaks are not always exposed as they are found even where no breaking of the. ontermost layers of cells has taken place. Together with these dis- 
tinctly brownish-colored areas there may also be present in the interior of stalks small longitudinal and light-colored areas where the parenchyma cells have entirely collapsed and leaving an empty cavity of a millimeter or more in width and of variable length. Microscopic sections of the discolored areas in yellow-striped cane stalks show that some parenchyma cells are full of a more or lesis

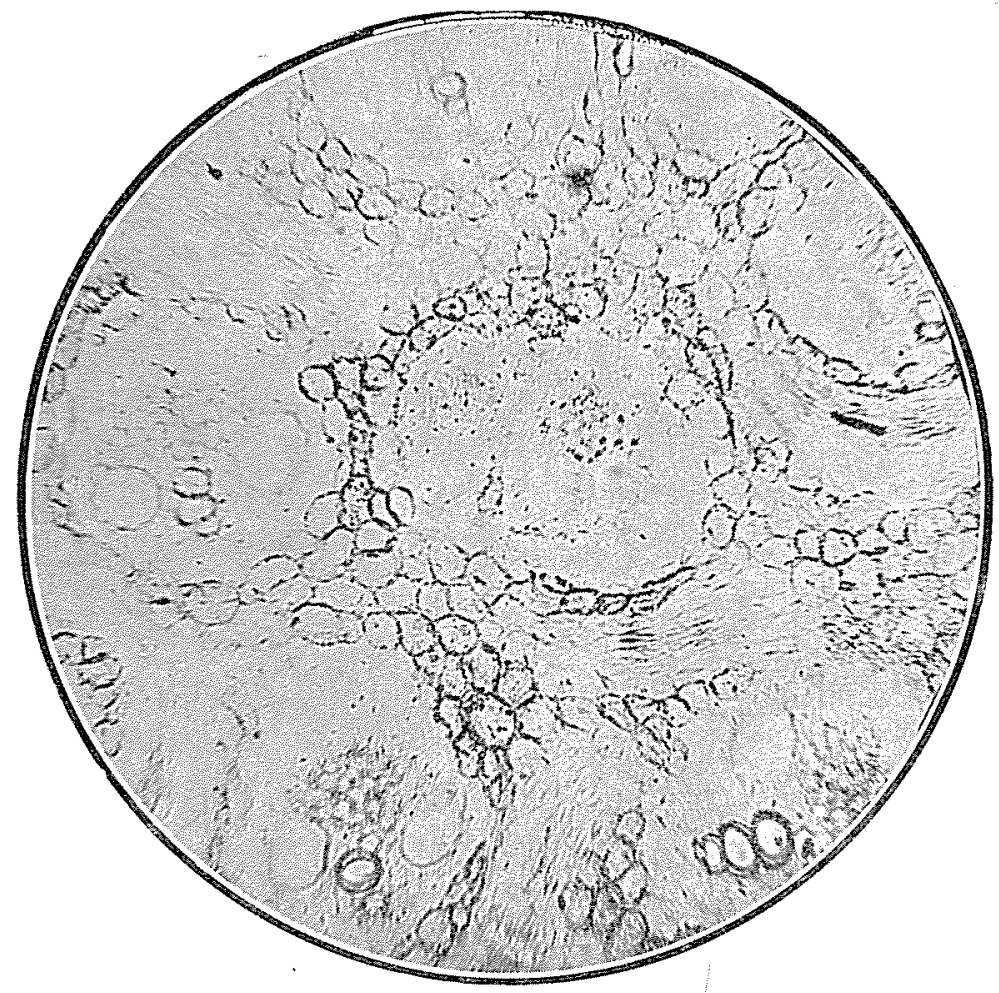

Frg. 4.-Photograph of a cross section through a growing point of a healthy cane stalk. $(\times 50$.

hardened or compact, densely but finely granulated, and slightly browned plasma. (Fig. 7.) Usually there are small groups of a few cells thus filled, but it is not uncommon to find only a single cell (Fig. 8), full of the granular material while the surrounding cells only show a slight brownish discoloration in their walls. This phenomenon is common in older portions of more or less full-grown cankered cane, especially where an alteration in color exists in the 
stem tissue. It has also been observed in leaf sheaths of yellow-stripe diseased cane. Here it is found in slightly depressed areas on the inner side of apparently uninjured leaf sheaths. It seems that the

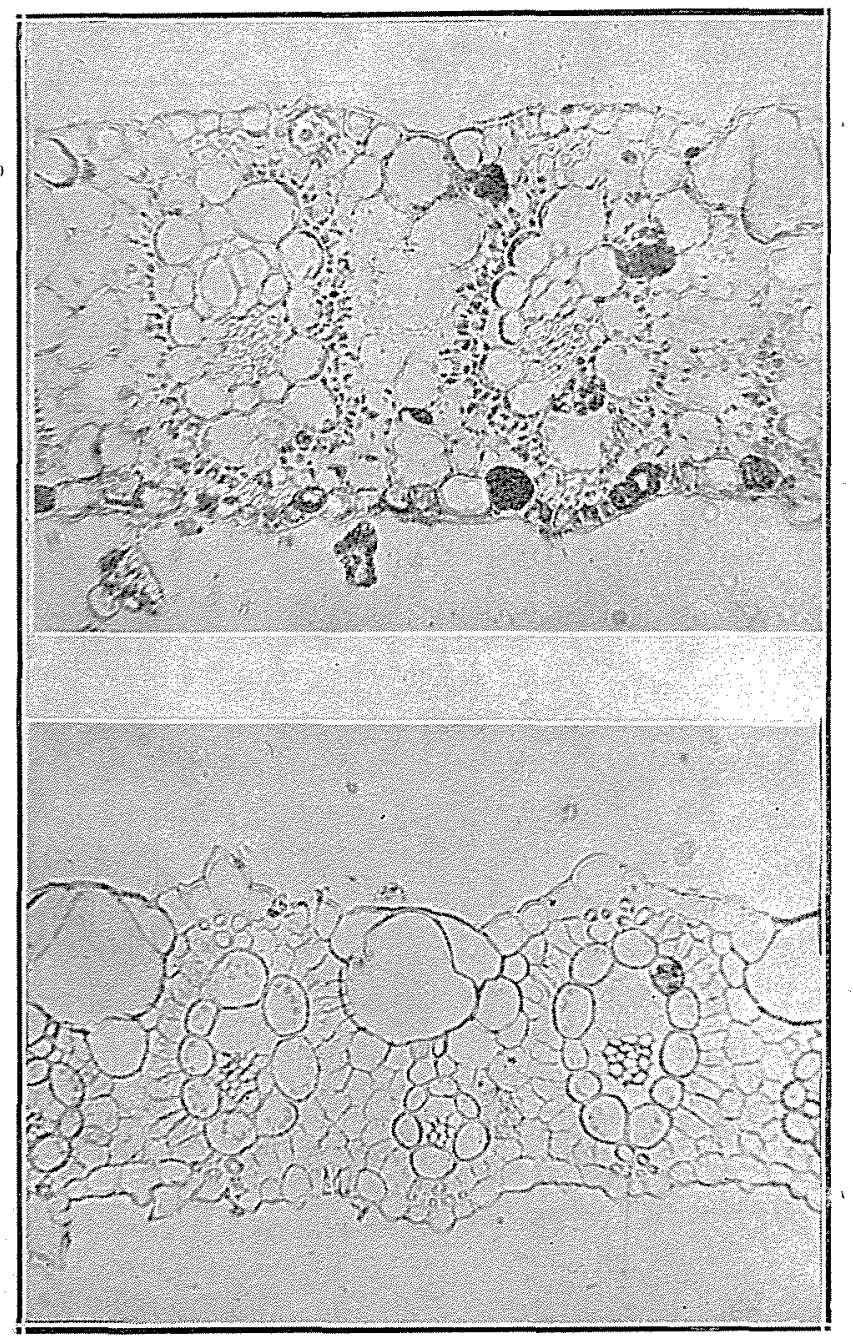

FIGs. 5 and 6.-Upper figure is a photograph of a cross section through a yellow-stripe diseased cane leaf. The lower figure is a photograph of a cross-section through a healthy cane leaf. $(\times 100$.

plugging of parenchyma cells in this manner is a diagnostic feature peculiar to yellow-stripe disease.

Free hand sections and sections from tissue which was fixed and 
killed and imbedded in paraffine, from internal portions of cankered cane, were treated in the usual way, $i$. e., dehydrated with alcohol and cleared with xylol. The cells which contained the dense and finely granulated substance did not lose it in the process of mounting.

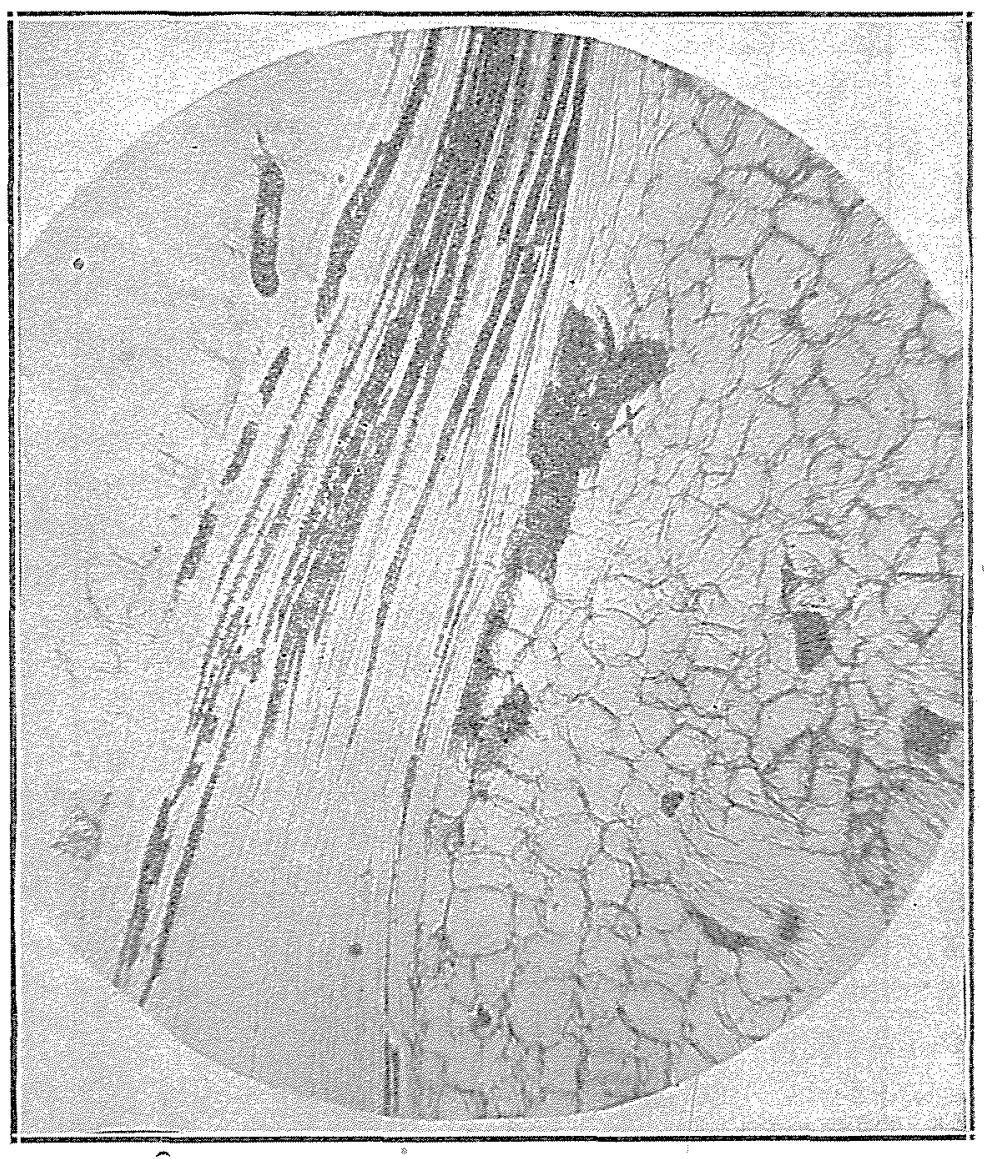

FIG. 7.-Photograph of a longitudinal section through a node of yellow-stripe diseased and cankered cane, showing a group of plasmafilled cells at $X . \quad(X 50$.

In examining these sections with the microscope it is at onee apparent that the granular substance is made up of a mass of smant hyaline bodies more or less miform in size. However, their exact size and form could not be ascertained, due to the fact that the whole mass is in the form of a compact plasma. The hyaline bodies 
which are dotted throughout the mass are less than one micron in length in sections from freshly cut cankered cane. They more nearly resemble nuclear granules in a mass of cytoplasm. They are less clearly defined than masses of bacteria.

Early attempts to induce growth development in agar from the above plasma-filled cells have failed. It was thought advisable to observe the condition of cankered cane in more than one stage.

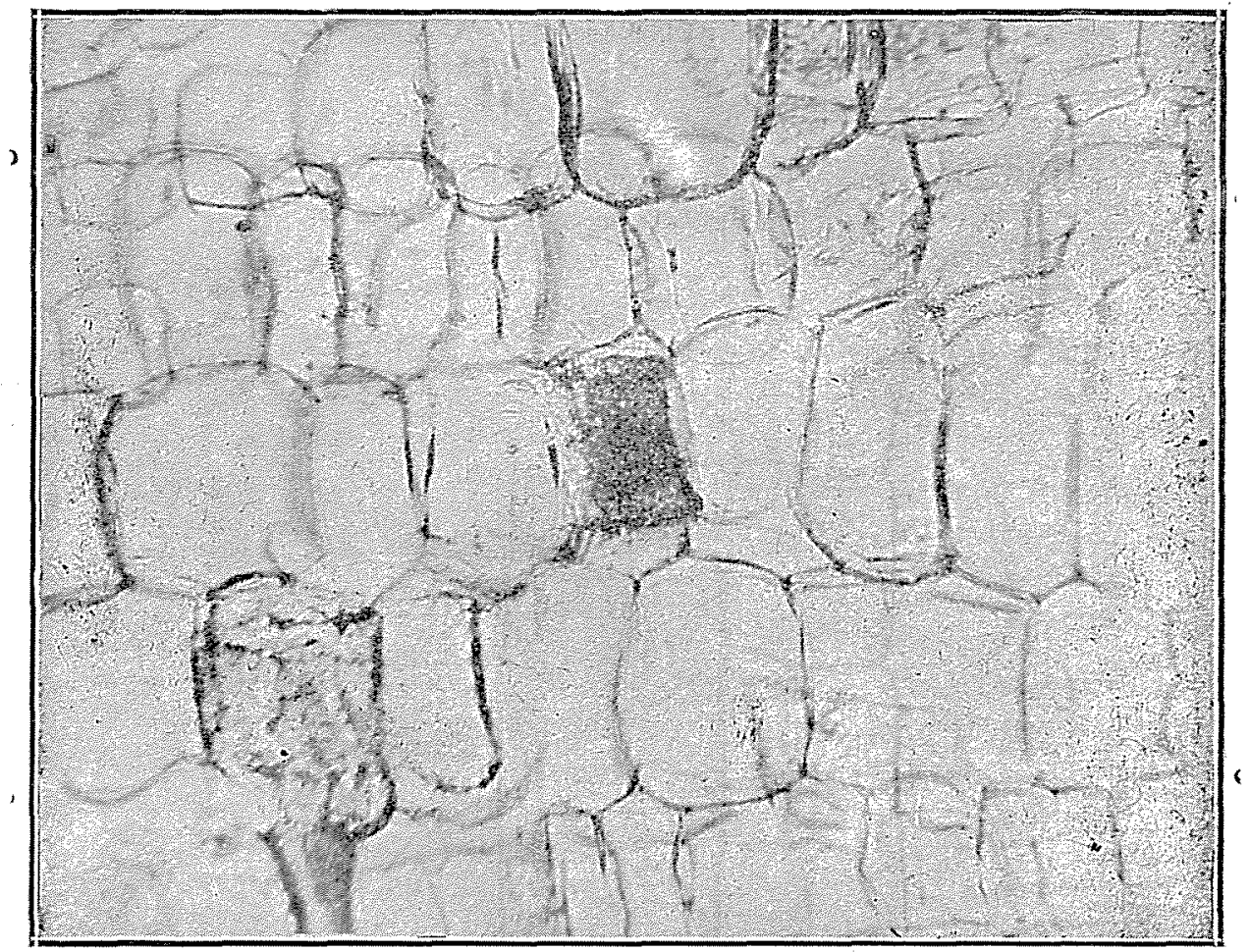

Frg. 8.-Photograph of a section through an interior canker of yellow-stripe diseased cane, showing in the center and near the lower left-hand corner single cells filled with finely granular plasma. $(\times 250$.

Therefore such cane was collected from three different parts of the Island, south coast, north coast, and northeast section. The local and scattered plasma-filled cells were found in the cane from the three parts mentioned and in the varieties Rayada, Cavengerie or red cane and other kinds. In growing cane the condition of the plasmafilled cells were similar in all canes examined. Some of the cankered cane was kept in a covered chamber for two months, so that the cane 
became devitalized and yet not much dried out. Free hand sections of this material showed the granular plasma material in the parenchyma cells in the same proportion as in freshly cut cane, but the

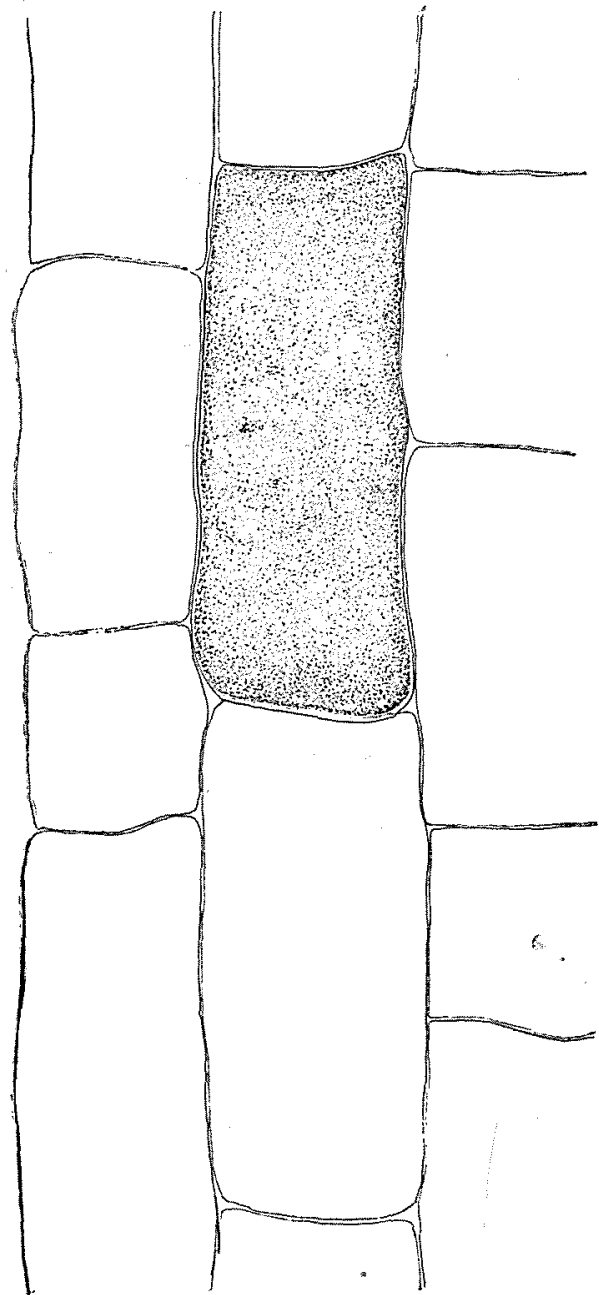

FIG. 9.-Camera lucida drawing of a plasma-filled cell in an internally diseolored area in yellow-stripe diseased cane stalk. (X333.)

granules in the former were more distinct, irregular in form, elongated and somewhat larger. In addition rotary movement of the individual minute bodies within the host cells was distinctly notice- 
able. It appeared that growth or a separation into more distinct individuals took place. It was very clear from the material at hand that the compact plasma in the cells of freshly cut cankered cane were in every way similar in appearance and distribution to the plasma in the cells which were seen in the more devitalized cane, only that in the latter more distinctness was observable. However, it was felt that sugar-cane treated in this manner is bound to become overrun with microorganisms and so more cankered cane was obtained, sterilized in bichloride of mercury and kept in the moist chamber for daily observation. It was found that in the course of two days some

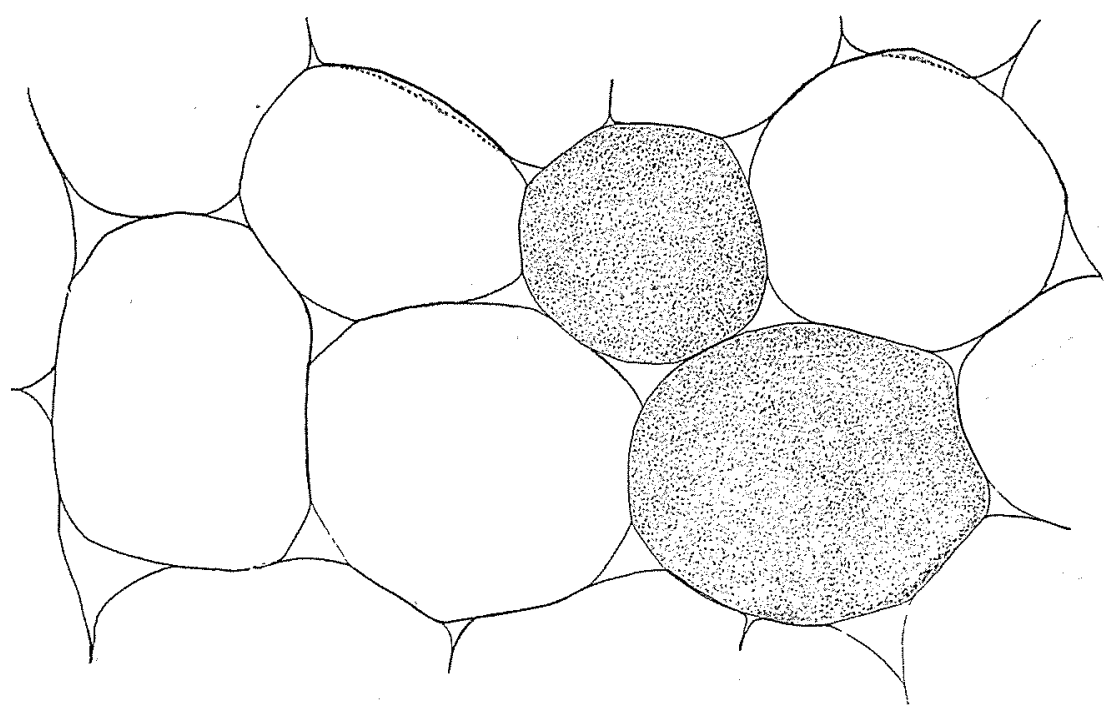

FIG. 10.-Same as in Fig. 9, in cross section. ( $\times 333$.

cankered cane showed a greater distinctness in the granulation of the characteristic plasma-filled cells, and that after eight days motility was observed in the plasma mass. As to the exact nature of this organism in the cankered cane cells nothing more definite can be said until more data is obtained in the process of investigation.

In cane otherwise diseased or injured by borers or fungi a reddish discoloration usually is found, but it is more or less continuous and is confined more to the vascular bundles. Such bundles often contain a homogeneous gummy substance which is not at all like the substance in cankered cane parenchyma cells. Discoloration of 
parenchyma cells in non-yellow striped cane may also occur but the discoloration is not of the same character as in yellow-stripe disease tissue. In cane diseased because of an invasion of fungi or other destructive agents the discoloration is more confined to the phloem and vessels and to the cell walls of parenchyma. A red phloem and gummed vessels are signs of wilt and decay due to fungi, bacteria, insects or mechanical injury. A continuous cavity in the pith or center of the stalk is a common effect of fungus invasion.

Further work is being done and planned with the view to clear up some of the phases of the problem of yellow-stripe disease.

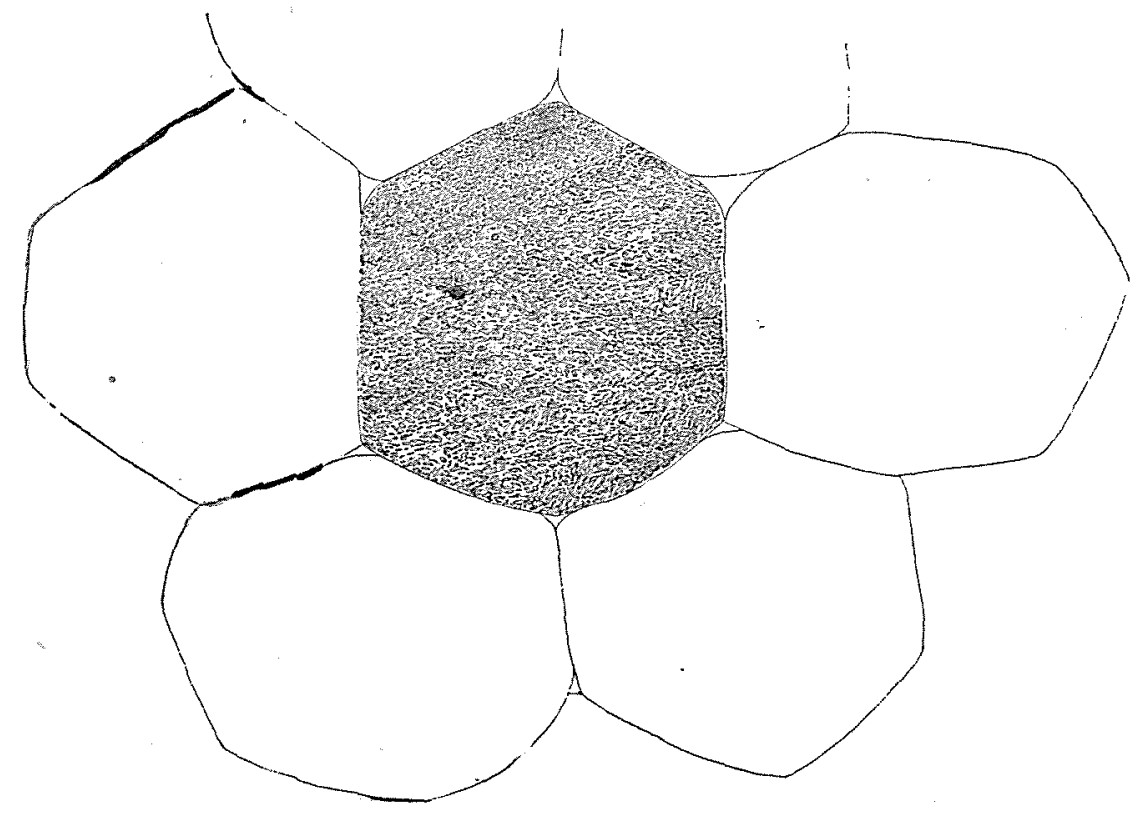

FIG. 11.-Drawing of a section of yellow-stripe diseased cane tissue two months after the cane was cut. $(\times 400$.)

From a study of the internal structure of cankered cane it is clear that actual deterioration and breaking down of cells in the interior of cane in an advanced stage of the yellow-stripe disease takes place. This effect is due to no other cause than to the destructive action of the infective substance of yellow-stripe disease, as there is apparently no connection between these interior sick cells and other outside mechanical or organized agencies. Furthermore, this substance, resembling a Plasmodium, in some of the interior cells was found to be constantly associated with yellow-striped cane in an advanced stage of disease. 